\title{
Desempenho bioeconômico de tourinhos alimentados com níveis de concentrado e farelo do mesocarpo de babaçu
}

\section{Bioeconomic performance of young bulls fed levels of concentrate and babassu mesocarp bran}

\author{
Rossini Sôffa da Cruz ${ }^{1}$; Emerson Alexandrino ${ }^{2}$; Regis Luis Missio ${ }^{3 *}$ João Restle; \\ Jonahtan Chaves Melo ${ }^{1}$; Joaquim José de Paula Neto ${ }^{1}$; José Neuman Miranda \\ Neiva $^{2}$; Gilson de Oliveira Mendes Filho ${ }^{1}$; Antonio de Souza Júnior ${ }^{1}$; Tatielle \\ Duarte e Duarte $^{1}$; José Messias de Rezende ${ }^{1}$; André Augusto Marinho Silva ${ }^{1}$
}

\section{Resumo}

Objetivou-se avaliar o desempenho bioeconômico de tourinhos alimentados com níveis de concentrado e farelo do mesocarpo de babaçu (FMB). Foram utilizados 28 tourinhos Nelore com 21 meses de idade e $356,7 \pm 19,2 \mathrm{~kg}$ de peso corporal inicial, distribuídos ao acaso em dietas que associaram dois níveis de concentrado ( 65 e $71 \%$ ) e dois níveis de FMB no concentrado (zero e $35 \%$ ). O delineamento experimental utilizado foi o inteiramente casualizado, com os tratamentos em arranjo fatorial $2 \times 2$, utilizando-se sete repetições. A digestibilidade aparente da matéria seca decresceu 15,8\% pela inclusão do FMB e 4,6\% pelo aumento do nível de concentrado da dieta. O consumo de matéria seca (CMS, $\mathrm{kg} / \mathrm{dia})$ e fibra em detergente neutro (CFDN, kg/dia) aumentaram, respectivamente, 8,7 e 24,8\% pela inclusão do FMB. O aumento do nível de concentrado não alterou o CMS, mas determinou redução do $\mathrm{CFDN}$ em 4,5\%. A inclusão de 35\% de FMB no concentrado determinou redução do custo com alimentação e custo total, entretanto não alterou a margem de lucro. A elevação do nível de concentrado da dieta determinou elevação do custo com alimentação e do custo total, mas não alterou a margem de lucro. Pela análise de sensibilidade verificou-se que quando a relação de troca entre o preço do grão de milho e do FMB é baixa (1,3:1 e 1,7:1) e, consequentemente, o preço do milho é baixo, a inclusão de $35 \%$ de FMB no concentrado não altera o custo total, independente do nível de concentrado. A inclusão de $35 \%$ de FMB na fração concentrada da dieta é alternativa alimentar viável, pois não altera o desempenho de tourinhos confinados. Entretanto, sua utilização é mais impactante economicamente quando se utilizam dietas com elevada proporção de concentrado e a relação de troca entre o preço desse subproduto e o grão de milho é alta.

Palavras-chave: Biocombustível, bovinos, custo, digestibilidade, ganho de peso

\footnotetext{
Abstract

This study aimed to assess the bioeconomic performance of young bulls fed levels of concentrate and babassu mesocarp bran (BMB). Twenty-eight Nellore young bulls, 21 months of age and $356.7 \pm 19.2$ $\mathrm{kg}$ of initial body weight, were randomly assigned to diets that combined two concentrate levels (65

${ }^{1}$ Discentes, Universidade Federal do Tocantins, UFT, Araguaína, TO. E-mail: rossinizoot@hotmail.com; jonahtancmelo@hotmail. com; jneto@zootecnista.com.br; gilsonfilho20@hotmail.com; antonioojunioor@hotmail.com; tatielleduarte18@yahoo.com.br; messyas10@hotmail.com; andre_augusto89@hotmail.com

2 Profs., Universidade Federal do Tocantins, UFT, Araguaína, TO. E-mail: e_alexandrino@yahoo.com.br; araguaia2007@gmail. com

3 Prof., Universidade Tecnológica Federal do Paraná, UTFPR, Pato Branco, PR. E-mail: regisluismissio@gmail.com

${ }^{4}$ Pesuisador, Universidade Federal do Tocantins, UFT, Araguaína, TO. E-mail: restle@terra.com.br

* Autor para correspondência
} 
and $71 \%$ ) and two levels of BMB (zero and $35 \%$ ). The experimental design used was the completely randomized design with treatments in a $2 \times 2$ factorial arrangement, using seven replicates. The apparent digestibility of dry matter decreased by $15.8 \%$ by the inclusion of BMB and $4.6 \%$ by increasing the level of concentrate in the diet. The intakes of dry matter (DMI, $\mathrm{kg}$ /day) and neutral detergent fiber (NDF, $\mathrm{kg} /$ day) increased, respectively, 8.7 and $24.8 \%$ by the inclusion of the BMB. The increase of the level of concentrate did not alter the DMI, but caused decrease of NDFI by $4.5 \%$. The inclusion of $35 \%$ of BMB in the concentrate reduced the feed cost and total cost, however did not affect the profit margin. The elevation of the level of concentrate in the diet determined elevation of feed cost and total cost, but did not alter the profit margin. According to the sensitivity analysis when the exchange ratio between the price of corn grain and FMB is low (1.3:1 and 1.7:1) and consequently the price of corn is low, the inclusion of $35 \%$ of $\mathrm{BMB}$ in the concentrate does not change the total cost, regardless of the level of concentrate. The inclusion of $35 \%$ of the $\mathrm{BMB}$ in the concentrated is a viable alternative, since it does not change the feedlot performance of young bulls. However, its use is more economically impactful when using diets with high concentrate and the exchange ratio between the price of this byproduct and corn is high.

Key words: Biofuel, cattle, cost, digestibility, weight gain

\section{Introdução}

O Brasil está inserido no mercado internacional como um dos principais produtores de carne bovina, apresentando o maior rebanho comercial de bovinos, sendo considerado como um dos únicos países com reais condições de expandir a produção de carne. Entretanto, apesar da extensão territorial, das condições edafoclimáticas favoráveis para produção de forragem e elevado efetivo bovino, o Brasil apresenta taxa de abate de $23 \%$, considerada baixa em relação a outros países produtores, tal como EUA, Austrália e Nova Zelândia, os quais abatem em torno de 37, 30 e $40 \%$ de seu rebanho ao ano, respectivamente (ANUALPEC, 2011).

A baixa eficiência produtiva do sistema pecuário brasileiro está associada ao sistema de exploração extensiva e ao baixo nível tecnológico, onde a alimentação do rebanho é, na grande maioria, exclusivamente a pasto. Tal fato, determina que o desempenho dos animais durante o ano seja prejudicado, uma vez que a produção e a qualidade da forragem são fortemente influenciadas pelas condições edafoclimáticas, notadamente pelo regime de chuvas (período seco). A estacionalidade na produção das gramíneas tropicais determina diminuição da oferta de bovinos em condições de abate, fato que normalmente eleva o preço da carne ao consumidor e o preço pago ao produtor rural. Nesse período, a utilização do confinamento tem sido usual para a terminação de bovinos, contribuindo para manutenção da oferta de carne no mercado interno. Entretanto, essa tecnologia tem sido prejudicada economicamente em função do custo com alimentação, onde parte significativa desse custo está relacionada à fração concentrada da dieta, a qual pode representar $65 \%$ deste custo, variando em função do teor de concentrado da dieta (MISSIO et al., 2009).

A redução do custo com alimentação pode ser viabilizada pela utilização de silagens de boa qualidade associada à redução da proporção de concentrado e/ou pela utilização de produtos alternativos ao milho e farelo de soja da dieta. Essa alternativa tem relativa importância quando considerado a utilização de dietas com elevadas proporções de concentrado, muito utilizadas em confinamentos industriais. Além disso, devese considerar que o aporte nutricional imposto aos animais em confinamento, determinado pela proporção de concentrado e/ou pela composição da dieta, determina diferenças quanto ao desempenho animal, bem como quanto aos custos de produção e, consequentemente, quanto a margem de lucro do sistema de terminação (FATURI et al., 2003; EZEQUIEL et al., 2006; MISSIO et al., 2009), tornando justificáveis pesquisas com diferentes alimentos e formulações, notadamente quando da utilização de subprodutos agroindustriais. 
$\mathrm{Na}$ região Norte, tem sido ofertado no mercado, quantidade considerável de farelo do mesocarpo do babaçu. Este subproduto é originado do processamento do fruto da palmeira do babaçu (Orbygnya ssp.) para a exploração do óleo de sua amêndoa para produção biodiesel (MIOTTO, 2011). Além do baixo custo, o farelo do mesocarpo de babaçu apresenta teor de amido na ordem de 52\% (PAVLAK et al., 2007), fato que tem tornado este subproduto uma opção para a alimentação animal. No entanto, é restrito o número de informações relacionadas com o desempenho animal e aspectos de sua digestão ruminal, assim como quanto à viabilidade econômica de sua utilização para terminação de bovinos em confinamento. Dessa forma, objetivou-se avaliar o desempenho bioeconômico de tourinhos alimentados com dois níveis de concentrado associado ou não à inclusão do farelo do mesocarpo do babaçu na fração concentrada da dieta.

\section{Material e Métodos}

Foram utilizados 28 tourinhos da raça Nelore, contemporâneos, com idade inicial de 21 meses e $356,66 \pm 19,25 \mathrm{~kg}$ de peso corporal inicial, distribuídos inteiramente ao acaso em dietas que associaram dois níveis de concentrado (65 e 71\%) e dois níveis (zero e 35\%) de farelo do mesocarpo de babaçu (FMB) no concentrado (Tabela 1). Os animais, submetidos a 15 dias de adaptação às dietas e instalações, foram confinados individualmente em baias $\left(14 \mathrm{~m}^{2}\right)$ parcialmente cobertas e alimentados à vontade, em duas refeições diárias, as oito e às 17 horas, durante 77 dias.

Tabela 1. Composição percentual, química e custo das dietas experimentais.

\begin{tabular}{|c|c|c|c|c|}
\hline \multirow{4}{*}{ Itens } & \multicolumn{4}{|c|}{ Farelo do mesocarpo de babaçu no concentrado (\%) } \\
\hline & \multirow{2}{*}{\multicolumn{4}{|c|}{$\begin{array}{l}0 \\
\text { Nível de concentrado da dieta }(\%)\end{array}$}} \\
\hline & & & & \\
\hline & 65 & 71 & 65 & 71 \\
\hline SCP, $\% \mathrm{MS}$ & 35,00 & 29,00 & 35,00 & 29,00 \\
\hline FMB, \% MS & -- & -- & 22,68 & 25,46 \\
\hline GMM, \% MS & 54,97 & 62,80 & 32,46 & 36,74 \\
\hline FS, \% MS & 7,49 & 5,80 & 6,67 & 5,70 \\
\hline $\mathrm{UP}, \% \mathrm{MS}$ & 0,91 & 0,88 & 1,51 & 1,50 \\
\hline $\mathrm{CC}, \% \mathrm{MS}$ & 0,82 & 0,78 & 0,81 & 0,77 \\
\hline NM, \% MS & 0,51 & 0,44 & 0,51 & 0,48 \\
\hline $\mathrm{SC}, \% \mathrm{MS}$ & 0,21 & 0,20 & 0,20 & 0,19 \\
\hline $\mathrm{SA}, \% \mathrm{MS}$ & 0,09 & 0,10 & 0,17 & 0,17 \\
\hline MS, \% & 70,00 & 72,67 & 70,10 & 72,80 \\
\hline MM, \% MS & 5,98 & 5,52 & 7,08 & 6,77 \\
\hline $\mathrm{PB}, \% \mathrm{MS}$ & 12,46 & 12,00 & 12,58 & 12,24 \\
\hline FDN, \% MS & 28,43 & 24,86 & 32,88 & 29,85 \\
\hline NIDN, \% NT & 5,62 & 5,35 & 8,34 & 8,47 \\
\hline NIDA, $\%$ NT & 3,15 & 3,06 & 4,57 & 4,68 \\
\hline $\mathrm{CT}, \% \mathrm{MS}$ & 79,89 & 80,38 & 81.65 & 82,07 \\
\hline $\mathrm{CNF}, \% \mathrm{MS}$ & 51,47 & 55,51 & 48,77 & 52,22 \\
\hline NDT, \% MS & 73,84 & 76,04 & 67,33 & 68,69 \\
\hline Custo, R\$/kg & 0,32 & 0,34 & 0,29 & 0,30 \\
\hline
\end{tabular}

$\mathrm{SCP}=$ silagem de capim Piatã; FMB = farelo do mesocarpo do babaçu $(\mathrm{MS}=85,5 \% \mathrm{MS} ; \mathrm{PB}=3,2 \% \mathrm{MS} ; \mathrm{FDN}=31,6 \% \mathrm{MS}$; $\mathrm{NIDN}=0,3 \% \mathrm{MS} ; \mathrm{NIDA}=0,17 \% \mathrm{MS}$; CT = 92,1 \% MS; CNF = 64,6 \% MS; NDT = 61,5\% MS); GMM = grão de milho moído; FS = farelo de soja; $\mathrm{UP}=$ uréia pecuária; $\mathrm{CC}=$ calcário calcítico; $\mathrm{NM}=$ núcleo mineral $(\mathrm{Ca}=118 \mathrm{~g} / \mathrm{kg}, \mathrm{P}=90 \mathrm{~g} / \mathrm{kg}) ; \mathrm{SC}=$ sal comum; $\mathrm{AS}=$ sulfato de amônio; $\mathrm{MS}=$ matéria seca; $\mathrm{MM}=$ matéria mineral; $\mathrm{PB}=$ proteína bruta; FDN = fibra em detergente neutro; NIDN = nitrogênio em detergente neutro; NIDA = nitrogênio insolúvel em detergente ácido; $\mathrm{CT}=$ carboidratos totais; $\mathrm{CNF}$ = carboidratos não fibrosos; NDT = nutrientes digestíveis totais; NT = nitrogênio total.

Fonte: Elaboração dos autores. 
As dietas, isonitrogenadas, foram balanceadas para ganho de peso de $1,2 \mathrm{~kg} / \mathrm{dia}$, considerando consumo de $2,4 \%$ do peso corporal segundo NRC (1996). O consumo de alimento foi registrado diariamente, pela pesagem do alimento oferecido e das sobras. A oferta de alimento foi mantida em $10 \%$ acima do consumo voluntário, fornecida em duas refeições diárias (08h00 e 14h00). O volumoso utilizado durante o período de confinamento foi a silagem de Brachiaria brizantha cv. Piatã, colhida e desintegrada (partículas de 8-10 mm) em estágio inicial de florescimento das plantas e, o farelo do mesocarpo de babaçu (FMB) foi obtido pela extração da casca do fruto do babaçu separada do epicarpo, sendo posteriormente moída.

Os animais foram pesados individualmente no início do experimento e a cada 28 dias, exceto a última pesagem que ocorreu em intervalo de 21 dias, após jejum de sólidos e líquidos de 14-16 horas. Ao atingirem o peso de abate preconizado (460 kg) os animais foram abatidos em frigorífico comercial.

Para determinação da composição das dietas e consumo de nutrientes, amostras de alimentos e sobras foram coletadas semanalmente, as quais foram pré-secas em estufa com circulação forçada de ar à $55^{\circ} \mathrm{C}$ por 72 horas e processadas em moinho tipo Willey com peneira com crivos de $1 \mathrm{~mm}$. Nessas amostras foram determinados os teores de matéria seca (MS), matéria mineral (MM), proteína bruta (PB) e extrato etéreo (EE) segundo AOAC (1995). Os teores de nitrogênio insolúvel em detergente neutro (NIDN) e insolúvel em detergente ácido (NIDA) foram determinados segundo Licitra, Hernandez e Van Soest (1996). O teor de fibra em detergente neutro (FDN) foi determinado segundo Van Soest, Robertson e Lewis (1991). Os teores de fibra em detergente ácido (FDA) e lignina foram determinadas segundo Van Soest (1973). Os teores de carboidratos totais (CT), carboidratos não fibrosos (CNF) e nutrientes digestíveis totais (NDT) foram determinados segundo Sniffen et al. (1992), onde: $\mathrm{CT}=100-(\mathrm{PB}+\mathrm{EE}+\mathrm{MM}), \mathrm{CNF}=100-$ $(\mathrm{PB}+\mathrm{EE}+\mathrm{MM}+\mathrm{FDN})$ e $\mathrm{NDT}=\mathrm{PB}$ digestível + FDN digestível + CNF digestível $+(2,25$ x EE digestível).

$\mathrm{O}$ ensaio de digestibilidade foi realizado em três dias consecutivos, realizando-se coleta manual de $300 \mathrm{~g}$ de fezes durante a defecação espontânea dos animais. Essas foram processadas e analisadas quanto aos teores de MS, MM, FDN e CNF conforme mencionado anteriormente. A excreção de MS fecal foi estimada a partir da técnica de indicador interno (COCHRAN et al., 1986), sendo a fibra indigestível em detergente neutro (FDNi) o indicador adotado. O teor de FDNi das amostras de fezes, alimentos e sobras foi obtido após incubação in situ realizada em duas vacas mestiças de origem leiteira alimentadas com dietas similares por 240 horas (CASALI et al., 2008). A produção fecal (PF) foi determinada pela fórmula: $\mathrm{PF}$ ( $\mathrm{kg}$ de $\mathrm{MS} /$ dia) $=$ (consumo de FDNi/concentração de FDNi nas fezes) x 100. A digestibilidade foi determinada pela fórmula: digestibilidade $(\%)=[$ (nutriente ingerido - nutriente excretado)/nutriente ingerido] x 100.

A avaliação econômica foi realizada a partir das metodologias propostas por Kassai et al. (2000), Souza e Clemente (2004) e Pacheco et al. (2006). As dietas foram consideradas como projetos de investimento mutuamente excludentes, assumindose valores conhecidos para os itens que compõem os custos e receitas (Tabela 2) utilizados para o cálculo dos indicadores econômicos (Tabela 3), considerando os valores praticados no estado do Tocantins no ano de 2010. 
Tabela 2. Descrição dos itens de custos e receitas utilizados para cálculo dos indicadores econômicos, estimados por animal.

\begin{tabular}{|c|c|c|}
\hline Indicador & Unidade & Equação \\
\hline $\mathrm{CF}$ & $\mathrm{R} \$$ & $\begin{array}{l}=\text { depreciação (instalações, máquinas, implementos e equipamentos) }+ \text { oportunidade } \\
\text { (instalações, máquinas, implementos e equipamentos) }+ \text { oportunidade da terra }\end{array}$ \\
\hline $\mathrm{CV}$ & $\mathrm{R} \$$ & $\begin{array}{l}=\text { compra do animal magro + controle sanitário, alimentação com volumoso e concentrado } \\
+ \text { mão-de-obra e assistência técnica }+ \text { outras despesas }+ \text { oportunidade do capital investido }\end{array}$ \\
\hline $\mathrm{COE}$ & $\mathrm{R} \$$ & $\begin{array}{l}=\text { compra do animal magro }+ \text { controle sanitário, alimentação com volumoso e concentrado } \\
+ \text { mão-de-obra e assistência técnica }+ \text { outras despesas }\end{array}$ \\
\hline COT & $\mathrm{R} \$$ & $=\mathrm{COE}+$ depreciação (instalações, máquinas, implementos e equipamentos) \\
\hline $\mathrm{CT}$ & $\mathrm{R} \$$ & $=(\mathrm{CF}+\mathrm{CV})$ ou $(\mathrm{COT}+$ Oportunidades $)$ \\
\hline C/GMD & $\mathrm{R} \$ / \mathrm{kg}$ & $=($ custo total - custo do animal magro $) /$ ganho de peso total na terminação \\
\hline c/@ & $\mathrm{R} \$ / \mathrm{kg}$ & $=($ custo total $) /$ peso de carcaça quente \\
\hline Receita & $\mathrm{R} \$$ & $=($ peso de carcaça quente $/ 15) *$ preço da arroba do boi gordo \\
\hline
\end{tabular}

$\mathrm{CF}=$ custo fixo; $\mathrm{CV}=$ custo variável $; \mathrm{COE}=$ custo operacional efetivo; $\mathrm{COT}=$ custo operacional total; $\mathrm{CT}=$ custo total; $\mathrm{C} / \mathrm{GMD}$ = custo/ganho de peso médio diário; $\mathrm{C} / @=$ custo/@ de carcaça total.

Fonte: Elaboração dos autores.

Tabela 3. Descrição dos indicadores econômicos, estimados por animal.

\begin{tabular}{|c|c|c|}
\hline Indicador & Unidade & Equação \\
\hline MB & $\mathrm{R} \$$ & $=$ receita $-\mathrm{COE}$ \\
\hline ML & $\mathrm{R} \$$ & $=$ receita $-\mathrm{COT}$ \\
\hline Lucro & $\mathrm{R} \$$ & $=$ receita - custo total \\
\hline VPL & $\mathrm{R} \$$ & $\sum_{=i=1}^{n} \frac{\text { valores }_{i}}{(1+T M A)^{i}}$, onde $\mathrm{n}=$ número de fluxos de caixa e $T M A=$ taxa mínima \\
\hline IBC & & $\begin{array}{l}=\text { Valor presente dos fluxos de caixa positivos/valor presente dos fluxos de caixa } \\
\text { negativos }\end{array}$ \\
\hline ROIA & $\%$ a.m. & $\begin{array}{l}i=\sqrt{\frac{F V}{P V}-1} \\
=\quad \text {, onde } F V=\text { Valor Futuro é representado pelo IBC, } P V=\text { Valor } \\
\text { Presente, } n=\text { Período e } i=\text { Taxa de Juros, representa o ROIA }\end{array}$ \\
\hline TIR & $\%$ a.m. & $\begin{array}{l}-I+\sum_{t=1}^{n} \frac{F C_{t}}{(1+T I R)^{t}} \text {, onde: } I=\text { investimento de capital na data zero, } F C_{t}= \\
\text { retorno na data } t \text { do fluxo de caixa e } n=\text { prazo de análise do projeto }\end{array}$ \\
\hline
\end{tabular}

$\mathrm{MB}=$ margem bruta; $\mathrm{ML}=$ margem líquida $\mathrm{VPL}=$ valor presente líquido; $\mathrm{IBC}=$ índice benecício/custo; $\mathrm{ROIA}=$ retorno adicional sobre o investimento; TIR = taxa interna de retorno.

Fonte: Elaboração dos autores. 
O custo com depreciação foi determinado pelo método linear, considerando o valor de sucata de $10 \%$, em que as instalações, máquinas, implementos e equipamentos utilizados são listados na Tabela 4. O custo de oportunidade de instalações, máquinas, implementos e equipamentos foi determinado para o período de confinamento (77 dias), tendo considerando como taxa de atratividade mínima o rendimento da poupança $(0,5 \%$ a.m.). O custo de oportunidade da terra foi determinado considerando a área (ha) necessária para produção da quantidade de volumoso consumida pelo animal multiplicada pelo custo por ha/dia e período para produção, confecção e utilização do volumoso (120 dias). O custo por ha/dia foi determinado considerando que o arrendamento de 1 ha $=10$ sacos de soja, ou seja, $\mathrm{R} \$ 308,1 /$ ha/ano, obtendo-se o custo de R \$ 0,84/ha/ dia, sendo o preço médio da saca da soja de $\mathrm{R} \$ 30,81$. Para fins de comparação futura de resultados, considerou-se US $\$=\mathrm{R} \$ 1,74$ e IGPM $-\mathrm{FNP} / \mathrm{FGV}$ (índice geral de preços de mercado FNP/Fundação Getúlio Vargas) = valor em $\mathrm{R} \$ / 0,72$ (janeiro 1980 =100), multiplicando-se o valor do IGPM - FNP/ FGV obtido pelo IGPM- FNP/FGV de qualquer mês e ano (comparação dos valores em $\mathrm{R} \$$ ).

Tabela 4. Descrição dos itens considerados para o cálculo de depreciação.

\begin{tabular}{lcc}
\hline Itens & Vida útil (anos) & Custo (R\$) \\
\hline Confinamento comercial para 500 animais & 20 & $57.830,00$ \\
Centro de manejo com balança mecânica & 20 & $60.000,00$ \\
Galpão para armazenamento de ração & 20 & $30.000,00$ \\
Misturador horizontal & 20 & $4.500,00$ \\
Triturador de grãos & 20 & $3.500,00$ \\
Trator Massey Ferguson/Modelo 275/1994 & 15 & $70.000,00$ \\
Vagão forrageiro & 10 & $15.000,00$ \\
Colhedoura de forragem & 15 & $30.000,00$ \\
Equipamentos em geral & 2 & $4.000,00$ \\
\hline
\end{tabular}

Fonte: Elaboração dos autores.

O custo de aquisição do boi magro (junho de 2010) foi de R \$810,00/animal e o preço de comercialização da arroba do boi gordo (setembro de 2010) foi de $\mathrm{R} \$ 80,00$. O custo com manejo sanitário levou em consideração o valor médio dos custos com esse ítem ao longo do período de confinamento. $\mathrm{O}$ custo com alimentação (volumoso + concentrado) foi determinado considerando o consumo de alimento e relação volumoso:concentrado da dieta. $\mathrm{O}$ custo do volumoso foi determinado segundo Pacheco et al. (2006), considerando produção média de 10 t/ha de matéria verde de silagem.

O custo com mão-de-obra foi de dois salários mínimos mensais $(\mathrm{R} \$ 1020,00)$ mais encargos sociais, considerando a necessidade de um homem para 300 bois confinados, correspondente às atividades de preparo e fornecimento da alimentação, limpeza das instalações e manejo dos animais. O custo com assistência técnica foi de quatro salários mínimos mensais (R $\$ 2040,00)$, considerando seis horas diárias para cada 1.000 animais em confinamento. O custo com outras despesas (combustível, energia elétrica, frete, prolabore do proprietário, impostos e alimentação da mão-de-obra) foi determinado considerando um valor fixo $(2,5 \%)$ em relação ao somatório dos custos com aquisição de animais, alimentação, mão-de-obra, controle sanitário e assistência técnica. O custo de oportunidade do capital investido foi determinado a partir do somatório dos custos com aquisição de animais, alimentação, mão-de-obra, controle sanitário, assistência técnica e outras despesas multiplicado 
pela taxa de juros média diária da poupança e dias de confinamento.

A análise de sensibilidade sobre o custo total e lucro foi determinada por meio da variação do preço do quilograma do grão de milho $(\mathrm{R} \$ 0,30 ; 0,40$; $0,50 ; 0,60$ e 0,70$)$, simulando-se diferentes relações de troca entre o preço do milho em grão em relação ao do $\operatorname{FMB}(1,3: 1 ; 1,7: 1 ; 2,2: 1 ; 2,6: 1$ e 3,0:1), mantendo-se as demais condições constantes. Após a análise de sensibilidade, os dados de cada simulação foram analisados em conjunto a fim de se conhecer o efeito da variação da relação de troca entre os dois alimentos de acordo com o nível de concentrado da dieta e o nível de inclusão do FMB na fração concentrada da dieta.

O delineamento experimental utilizado foi $\mathrm{o}$ inteiramente casualizado, com os tratamentos em arranjo fatorial $2 \times 2$ (dois níveis de concentrado e dois níveis de FMB no concentrado), utilizando-se sete repetições (animais). Os dados foram submetidos a análise de normalidade e homogeinidade de variâncias e, depois de satisfeitas essas pressuposições, os dados foram submetidos a análise de variância e as médias foram comparadas pelo teste Tukey ( $\alpha=5 \%$ ), utilizando-se o SAS statistical software (version 8.02). O modelo matemático geral utilizado foi: $\mathrm{g}_{\mathrm{ijk}}=\mu+\pi \mathrm{i}+\mathrm{t}_{\mathrm{j}}+$ $(\pi \mathrm{t})_{\mathrm{ij}}+\mathrm{e}_{\mathrm{ijk}}$, onde: $\mathrm{g}_{\mathrm{ijk}}=$ variável dependente; $\mu=$ média geral; $\pi \mathrm{i}=$ efeito do nível de FMB; $\mathrm{t}_{\mathrm{j}}=$ efeito do nível de concentrado $\mathrm{j} ;(\pi \mathrm{t})_{\mathrm{ij}}=$ interação entre nível de FMB i e nível de concentrado j; $\mathrm{e}_{\mathrm{ijk}}=$ erro experimental residual. Para a análise de sensibilidade o modelo matemático utilizado foi: $\mathrm{g}_{\mathrm{ijkl}}=\mu+\pi \mathrm{i}+\mathrm{t}_{\mathrm{j}}$ $+(\pi \mathrm{t})_{\mathrm{ij}}+\mathrm{b}_{\mathrm{k}}+(\pi \mathrm{b})_{\mathrm{ik}}+(\mathrm{tb})_{\mathrm{jk}}+(\pi \mathrm{tb})_{\mathrm{ijk}}+\mathrm{e}_{\mathrm{ijkl}}$ onde: $\mathrm{g}_{\mathrm{ijkl}}$ $=$ variável dependente; $\mu=$ média geral; $\pi \mathrm{i}=$ efeito do nível de FMB; $\mathrm{t}_{\mathrm{j}}=$ efeito do nível de concentrado $\mathrm{j} ;(\pi \mathrm{t})_{\mathrm{ij}}=$ interação entre nível de FMB i e nível de concentrado $\mathrm{j} ; \mathrm{b}_{\mathrm{k}}=$ efeito da relação de troca $\mathrm{k} ;(\pi \mathrm{b})$ ${ }_{\mathrm{ik}}=$ interação entre nível de FMB i e relação de troca $\mathrm{k} ;(\mathrm{tb})_{\mathrm{jk}}=$ interação entre nível de concentrado j e relação de troca $\mathrm{k} ;(\pi \mathrm{tb})_{\mathrm{ijk}}=$ interação entre nível de FMB i, nível de concentrado j e relação de troca k; $\mathrm{e}_{\mathrm{ijkl}}=$ erro experimental residual.

\section{Resultados e Discussão}

Não foi verificado intereção ( $\mathrm{P}>0,05)$ entre nível de FMB e nível de concentrado da dieta para as varaiáveis referentes a digestibilildade e consumo das frações alimentares, desempenho animal e avaliação econômica. Sendo assim, os resultados foram apresentados em função dos efeitos principais.

A inclusão do FMB determinou elevação $(\mathrm{P}<0,05)$ do consumo de matéria seca $(\mathrm{CMS})$, proteína bruta $(\mathrm{CPB})$, fibra em detergente neutro (CFDN) e carboidratos totais (CCT) (Tabela 5). Estes resultados refletiram a necessidade dos animais aumentarem o consumo de alimento para atendimento de seu requerimento energético, devido à menor contribuição energética do FMB em relação ao milho, tal como relatado por Cruz et al. (2012). Tais aspectos foram evidenciados ainda pelo similar $(\mathrm{P}>0,05)$ CCNF e CNDT ocorrido entre as dietas que não continham FMB em sua composição e aquelas com inclusão de $35 \%$ de FMB no concentrado (Tabela 4). Estes resultados foram semelhantes aos verificados por Miotto et al. (2013), os quais verificaram que o CMS, CPB e CFDN aumentaram e o CNDT não foi alterado pela inclusão de FMB na dieta de tourinhos da raça Nelore terminados em confinamento.

O CMS, CPB e CNDT não foram alterados $(\mathrm{P}>0,05)$, enquanto que o $\mathrm{CFDN}$ foi diminuído e o CCNF foi aumentado pela elevação do nível de concentrado da dieta (Tabela 5). Esses resultados foram coerentes com aqueles expostos por Restle et al. (2012), os quais argumentaram que, de forma geral, enquanto a quantidade de volumoso é superior, o incremento de concentrado eleva o CMS significativamente, mas quando a quantidade de concentrado passa a ser maior e o volumoso é de boa qualidade, o CMS chega ao ponto de inflexão da curva, onde tende a diminuir. Todavia, quando os níveis de concentrado são elevados e o volumoso é de média a baixa qualidade, o CMS tende a manterse constante com a elevação do concentrado na dieta (VÉRAS et al., 2008), situação similar à este estudo. 
Nesse caso, às reduzidas proporções de volumoso favoreceram o consumo de energia em ambos os níveis de concentrado, proporcionando a saciedade animal, tal como proposto por Van Soest (1994). De outra forma, a variação do CFDN e CCNF foram coerentes com os resultados apresentados por Tibo et al. (2000) e Missio et al. (2009), reflexo da diminuição dos teores de fibra em detergente neutro e do aumento do teor de carboidratos não fibrosos com a elevação do nível de concentrado na dieta, respectivamente.

Tabela 5. Consumo das frações alimentares e digestibilidade aparente das dietas de acordo com os níveis de farelo do mesocarpo de babaçu (FMB) e de concentrado (NC).

\begin{tabular}{|c|c|c|c|c|c|c|c|}
\hline \multirow{2}{*}{ Itens } & \multicolumn{2}{|c|}{ FMB (\%) } & \multicolumn{2}{|c|}{ NC (\%) } & \multicolumn{3}{|c|}{ Valor de P } \\
\hline & 0 & 35 & 65 & 71 & FMB & $\mathrm{NC}$ & $\mathrm{FMB} * \mathrm{NC}$ \\
\hline \multicolumn{8}{|c|}{ Consumo } \\
\hline MS, kg/dia & $9,50 \pm 0,8$ & $10,40 \pm 0,8$ & $9,88 \pm 0,8$ & $10,02 \pm 1,1$ & $<0,001$ & 0,449 & 0,194 \\
\hline $\mathrm{PB}, \mathrm{kg} / \mathrm{dia}$ & $1,18 \pm 0,2$ & $1,31 \pm 0,1$ & $1,26 \pm 0,1$ & $1,22 \pm 0,2$ & $<0,001$ & 0,137 & 0,642 \\
\hline $\mathrm{FDN}, \mathrm{kg} / \mathrm{dia}$ & $2,64 \pm 0,4$ & $3,51 \pm 0,3$ & $3,21 \pm 0,5$ & $2,94 \pm 0,6$ & $<0,001$ & $<0,001$ & 0,109 \\
\hline CT, kg/dia & $7,23 \pm 0,7$ & $8,01 \pm 0,7$ & $7,55 \pm 0,7$ & $7,68 \pm 0,9$ & $<0,001$ & 0,398 & 0,364 \\
\hline CNF, kg/dia & $4,22 \pm 0,5$ & $4,12 \pm 0,4$ & $3,93 \pm 0,4$ & $4,41 \pm 0,5$ & 0,280 & $<0,001$ & 0,540 \\
\hline NDT, kg/dia & $7,11 \pm 0,7$ & $7,09 \pm 0,6$ & $6,99 \pm 0,6$ & $7,21 \pm 0,7$ & 0,903 & 0,123 & 0,562 \\
\hline MS, \% PC & $2,29 \pm 0,3$ & $2,52 \pm 0,2$ & $2,40 \pm 0,2$ & $2,41 \pm 0,3$ & $<0,001$ & 0,761 & 0,166 \\
\hline $\mathrm{PB}, \% \mathrm{PC}$ & $0,29 \pm 0,1$ & $0,32 \pm 0,1$ & $0,31 \pm 0,1$ & $0,29 \pm 0,1$ & 0,003 & 0,194 & 0,483 \\
\hline FDN, \% PC & $0,65 \pm 0,1$ & $0,85 \pm 0,1$ & $0,78 \pm 0,1$ & $0,71 \pm 0,2$ & $<0,001$ & $<0,001$ & 0,291 \\
\hline CT, \% PC & $1,77 \pm 0,2$ & $1,95 \pm 0,2$ & $1,84 \pm 0,2$ & $1,87 \pm 0,2$ & $<0,001$ & 0,519 & 0,131 \\
\hline CNF, \% PC & $1,03 \pm 0,2$ & $1,00 \pm 0,1$ & $0,96 \pm 0,1$ & $1,07 \pm 0,1$ & 0,206 & $<0,001$ & 0,245 \\
\hline NDT, \% PC & $1,74 \pm 0,2$ & $1,73 \pm 0,1$ & $1,71 \pm 0,2$ & $1,76 \pm 0,2$ & 0,761 & 0,277 & 0,313 \\
\hline \multicolumn{8}{|c|}{ Digestibilidade } \\
\hline $\mathrm{MS}, \% \mathrm{MS}$ & $69,63 \pm 7,3$ & $58,66 \pm 4,2$ & $64,64 \pm 8,0$ & $61,65 \pm 8,4$ & $<0,001$ & 0,034 & 0,477 \\
\hline $\mathrm{MO}, \% \mathrm{MS}$ & $73,82 \pm 7,3$ & $61,26 \pm 5,1$ & $69,79 \pm 8,6$ & $66,30 \pm 9,3$ & $<0,001$ & $<0,001$ & 0,534 \\
\hline $\mathrm{PB}, \% \mathrm{MS}$ & $78,49 \pm 3,9$ & $69,70 \pm 5,1$ & $75,60 \pm 6,7$ & $72,72 \pm 6,1$ & $<0,001$ & 0,013 & 0,731 \\
\hline FDN, \% MS & $52,96 \pm 7,9$ & $37,53 \pm 8,0$ & $45,64 \pm 7,0$ & $44,85 \pm 6,9$ & $<0,001$ & 0,641 & 0,095 \\
\hline $\mathrm{CT}, \% \mathrm{MS}$ & $71,00 \pm 8,3$ & $59,00 \pm 5,3$ & $66,00 \pm 9,4$ & $64,00 \pm 9,7$ & $<0,001$ & 0,480 & 0,423 \\
\hline CNF, \% MS & $84,93 \pm 6,4$ & $70,09 \pm 5,5$ & $76,09 \pm 5,3$ & $78,94 \pm 7,0$ & $<0,001$ & 0,715 & 0,054 \\
\hline
\end{tabular}

$\mathrm{MS}=$ matéria seca; $\mathrm{PB}=$ proteína bruta; $\mathrm{FDN}=$ fibra em detergente neutro; $\mathrm{CT}=$ carboidratos totais; $\mathrm{CNF}=$ carboidratos não fibrosos; $\mathrm{NDT}=$ nutrientes digestíveis totais; $\mathrm{PC}=$ peso corporal; FMB*NC = interação entre FMB e NC.

Fonte: Elaboração dos autores.

A digestibilidade aparente da matéria seca (DAMS), matéria orgânica (DAMO), proteína bruta (DAPB), carboidratos não fibrosos (DACNF), carboidratos totais (DACT) e digestibilidade verdadeira da fibra em detergente neutro (DVFDN) diminuiu $(\mathrm{P}<0,05)$ pela inclusão do FMB no concentrado (Tabela 5), indicando alteração da taxa de passagem das dietas como resultado do reduzido tamanho de partícula do FMB. Miotto (2011) verificou que $96 \%$ das partículas do FMB apresentaram tamanho inferior a $1,18 \mathrm{~mm}$, granulometria, que segundo Mertens (1997), é insuficiente para estimular a ruminação. Nesse caso, o reduzido tamanho de partícula pode alterar o transito de alimento pelo retículo-rúmen, inibindo a formação de um emaranhado de fibras característico de dietas com elevado teor de volumoso (BULLE, 2000). A falta desta camada, responsável pela retenção de partículas pequenas de baixa digestibilidade, leva as partículas sólidas a deixar este compartimento mais rapidamente, sendo menos digeridas (VAN SOEST, 1994).

Os resultados apresentados foram coerentes com os obtidos por Guimarães (2010), o qual verificou redução da DAMS e DVFDN de dietas com silagem de capim Mombaça e teores crescentes de FMB (0, 4, 12 e 16\%) fornecidas para ovinos, fato atribuído à elevação do teor de lignina e ao baixo teor de 
proteína. Miotto et al. (2012) avaliando o FMB na dieta de ovinos verificou que a digestibilidade aparente da matéria orgânica diminuiu linearmente pela substituição da silagem de capim elefante pelo FMB (0, 21, 38, 62 e 78\%). Em experimento com com bovinos, Miotto et al. (2013) verificaram que a DAMS, DAPB, DVFDN e DACNF variaram de forma quadrática em função do nível de $\operatorname{FMB}(0,25$, 50, 75 e 100\%) em substituição ao milho da dieta, em que a digestibilidade mínima foi verificada nas dietas com $75 \%$ de FMB.

A elevação do nível de concentrado da dieta determinou redução $(\mathrm{P}<0,05)$ da DAMS e DAPB, mas não alterou a DAMO, DVFDN, DACT e DACNF (Tabela 5). Esses resultados discordaram daqueles apresentados por Tibo et al. (2000) e Silva et al. (2005), os quais verficaram que a digestibilidade das dietas aumentou com a elevação do nível de concentrado, refletindo o maior consumo de carboidratos não fibrosos. Além disso, Tibo et al. (2000) verificaram que o aumento do nível de concentrado da dieta $(25,0 ; 37,5 ; 50,0 ; 62,5$ e 75,0\%) promoveu redução da DVFDN e DACT como resultado da depressão da disgestibilidade ruminal da fibra. Destaca-se que os resultados apresentados não foram exclusividade do presente estudo, já que Pereira et al. (2006) verificaram redução da DAPB pelo aumento do nível de concentrado da dieta (20, 35,50 e $65 \%$ ), resultado do aumento do teor de NIDA das dietas, tal como no presente estudo (Tabela 1).

O ganho de peso médio diário (GMD) e o peso corporal final não foram alterados $(\mathrm{P}>0,05)$ pelas dietas experimentais (Tabela 6), refletindo o similar consumo de energia. No que se refere a utilização do FMB na dieta, os resultados obtidos foram similares aos verificados por Miotto et al. (2013) e Silva et al. (2012), os quais não verificaram variação do GMD de bovinos confinados em função do avanço do FMB em substituição ao grão de milho da dieta. Por outro lado, no que se refere aos níveis de concentrado, os resultados apresentados discordaram dos obtidos por Missio et al. (2009), os quais verificaram que o GMD aumentou pela elevação da fração concentrada da dieta, reflexo da elevação do consumo de alimento e energia digestível. No entanto, em situações em que o nível de concentrado não altera o CMS, bem como o de energia digestível, o desempenho animal não tem sido alterado (VÉRAS et al., 2008), corroborando com os resultados obtidos. É válido ressaltar que o GMD verificado neste estudo foi superior ao verificado por Silva et al. (2012), os quais verificaram valores médios de 1,$23 ; 1,14 ; 1,11$ e $1,16 \mathrm{~kg} /$ dia em novilhos Nelore alimentados com 0, 20, 40 e 60\% de FMB em substituição o grão de milho do concentrado, respectivamente.

As dietas experimentais não alteraram $(\mathrm{P}>0,05)$ a conversão alimentar (CA), a qual apresentou valor médio de $7,71 \mathrm{~kg}$ de matéria seca $/ \mathrm{kg}$ de ganho, sendo coerente com a categoria animal utilizada (Tabela 6). No que se refere a utilização do FMB, os resultados apresentados foram similares aos obtidos por Silva et al. (2012), os quais não verificaram alteração da CA pelo avanço do FMB no concentrado. Por outro lado, Mioto et al. (2013) verificaram redução da eficiência alimentar pelo avanço do FMB na dieta, refletindo o aumento do CMS. Quanto ao nível de concentrado, Resende et al. (2001) verificaram redução linear da CA com o incremento de concentrado na dieta $(15,30,45,60$ e $75 \%$ ), reflexo da elevação da densidade energética da dieta e menor quantidade de alimento necessária para o ganho de um quilo de peso corporal.

O custo fixo (Tabela 7), composto pelo custo de oportunidade da terra, custo com depreciações e juros sobre o capital empatado com instalações, máquinas, implementos e equipamentos, não foi alterado $(\mathrm{P}>0,05)$ pela inclusão do FMB no concentrado. Esses resultados refletiram a variação do CMS e o menor custo do FMB, visto que o CMS aumentou e o custo das dietas com FMB reduziu (Tabela 1). Contribuíram para estes resultados o similar período de confinamento. De outra forma, o custo fixo diminuiu $(\mathrm{P}<005)$ pelo aumento do teor de concentrado na dieta, refletindo a redução do custo de oportunidade da terra. Esses resultados foram similares aos obtidos por Missio et al. (2009), os quais verificaram que o custo de oportunidade da terra diminui pelo avanço do concentrado na dieta, refletindo a menor área exigida para produção de silagem. 
Tabela 6. Desempenho de tourinhos de acordo com os níveis de farelo do mesocarpo de babaçu (FMB) e de concentrado $(\mathrm{NC})$.

\begin{tabular}{llllllll}
\hline \multirow{2}{*}{ Itens } & \multicolumn{3}{c}{ FMB (\%) } & \multicolumn{2}{c}{$\mathrm{NC}(\%)$} & \multicolumn{3}{c}{ Valor de P } \\
\cline { 2 - 8 } & 0 & 35 & 65 & 71 & FMB & NC & FMB*NC \\
PCI, kg & $362,36 \pm 16,9$ & $368,93 \pm 19,2$ & $364,07 \pm 22,9$ & $367,21 \pm 12,1$ & 0,656 & 0,355 & 0,366 \\
PCF, kg & $464,21 \pm 19,9$ & $465,96 \pm 24,3$ & $464,82 \pm 24,7$ & $465,35 \pm 19,4$ & 0,951 & 0,841 & 0,376 \\
GMD, kg/dia & $1,32 \pm 0,2$ & $1,27 \pm 0,2$ & $1,31 \pm 0,1$ & $1,28 \pm 0,2$ & 0,141 & 0,987 & 0,436 \\
GPT, kg & $101,21 \pm 13,5$ & $95,00 \pm 14,3$ & $100,75 \pm 10,9$ & $99,61 \pm 16,7$ & 0,385 & 0,637 & 0,811 \\
CA, kg MS/GMD & $7,19 \pm 0,9$ & $8,22 \pm 1,2$ & $7,54 \pm 1,1$ & $7,88 \pm 1,0$ & 0,197 & 0,761 & 0,627 \\
\hline
\end{tabular}

$\mathrm{PCI}=$ peso corporal lincial; $\mathrm{PCF}=$ peso corporal final; GMD = ganho de peso médio diário; $\mathrm{GPT}=$ ganho de peso total; $\mathrm{CA}=$ conversão alimentar; $\mathrm{MS}=$ matéria seca; $\mathrm{FMB} * \mathrm{NC}=$ interação entre FMB e NC.

Fonte: Elaboração dos autores.

Tabela 7. Componentes do custo e receita, estimados por animal, de acordo com os níveis de farelo do mesocarpo de babaçu (FMB) e de concentrado (NC).

\begin{tabular}{|c|c|c|c|c|c|c|c|}
\hline \multirow{2}{*}{ Itens } & \multicolumn{2}{|l|}{ FMB (\%) } & \multicolumn{2}{|l|}{$\mathrm{NC}(\%)$} & \multicolumn{2}{|c|}{ Valor de P } & \multirow[b]{2}{*}{ FMB $* \mathrm{NC}$} \\
\hline & 0 & 35 & 65 & 71 & FMB & $\mathrm{NC}$ & \\
\hline $\mathrm{CF}, \mathrm{R} \$$ & $12,33 \pm 0,9$ & $12,42 \pm 0,9$ & $13,05 \pm 0,5$ & $11,70 \pm 0,5$ & 0,689 & $<0,001$ & 0,854 \\
\hline OT, R\$ & $7,03 \pm 0,9$ & $7,12 \pm 0,9$ & $7,75 \pm 0,6$ & $6,40 \pm 0,5$ & 0,693 & $<0,001$ & 0,868 \\
\hline $\mathrm{DEP}, \mathrm{R} \$$ & 5,24 & 5,24 & 5,24 & 5,24 & -- & -- & -- \\
\hline $\mathrm{OCD}, \mathrm{R} \$$ & 0,06 & 0,06 & 0,06 & 0,06 & -- & -- & -- \\
\hline $\mathrm{CV}, \mathrm{R} \$$ & $1099,69 \pm 19,9$ & $1084,33 \pm 13,6$ & $1086,41 \pm 15,4$ & $1097,61 \pm 20,2$ & 0,022 & 0,047 & 0,527 \\
\hline $\mathrm{A}, \mathrm{R} \$$ & 810,00 & 810,00 & 810,00 & 810,00 & -- & -- & -- \\
\hline $\mathrm{V}, \mathrm{R} \$$ & $48,83 \pm 6,2$ & $49,42 \pm 6,1$ & $53,83 \pm 3,8$ & $44,42 \pm 3,6$ & 0,688 & $<0,001$ & 0,864 \\
\hline $\mathrm{C}, \mathrm{R} \$$ & $161,65 \pm 6,2$ & $146,07 \pm 6,0$ & $143,69 \pm 11,8$ & $164,03 \pm 16,9$ & 0,003 & $<0,001$ & 0,441 \\
\hline ALI, R\$ & $210,48 \pm 19,5$ & $195,50 \pm 13,3$ & $197,53 \pm 15,0$ & $208,45 \pm 19,7$ & 0,022 & 0,047 & 0,527 \\
\hline $\mathrm{MO}, \mathrm{R} \$$ & 12,01 & 12,01 & 12,01 & 12,01 & -- & -- & -- \\
\hline $\mathrm{MS}, \mathrm{R} \$$ & 6,75 & 6,75 & 6,75 & 6,75 & -- & -- & -- \\
\hline $\mathrm{AT}, \mathrm{R} \$$ & 34,38 & 34,38 & 34,38 & 34,38 & -- & -- & -- \\
\hline $\mathrm{O}, \mathrm{R} \$$ & $26,07 \pm 0,5$ & $25,70 \pm 0,6$ & $25,75 \pm 0,4$ & $26,02 \pm 0,5$ & 0,022 & 0,047 & 0,529 \\
\hline OCI, R\$ & $11,27 \pm 0,2$ & $11,11 \pm 0,2$ & $11,13 \pm 0,2$ & $11,25 \pm 0,1$ & 0,022 & 0,048 & 0,512 \\
\hline $\mathrm{CT}, \mathrm{R} \$$ & $1112,02 \pm 20,3$ & $1096,75 \pm 13,9$ & $1099,46 \pm 15,9$ & $1109,31 \pm 20,7$ & 0,028 & 0,151 & 0,538 \\
\hline PCQ, kg & $258,50 \pm 13,3$ & $252,57 \pm 14,7$ & $258,07 \pm 14,7$ & $256,43 \pm 13,5$ & 0,497 & 0,757 & 0,699 \\
\hline REC, R\$ & $1377,52 \pm 70,8$ & $1357,33 \pm 78,5$ & $1362,87 \pm 78,5$ & $1372,00 \pm 71,9$ & 0,496 & 0,757 & 0,699 \\
\hline COE, R\$ & $1099,69 \pm 19,9$ & $1279,83 \pm 13,7$ & $1283,94 \pm 15,4$ & $1306,06 \pm 20,2$ & 0,022 & 0,047 & 0,527 \\
\hline COT, R\$ & $1104,93 \pm 19,9$ & $1285,07 \pm 13,7$ & $1289,18 \pm 15,4$ & $1311,30 \pm 20,2$ & 0,022 & 0,047 & 0,527 \\
\hline $\mathrm{R} \$ / \mathrm{GMD}$ & $2,98 \pm 0,3$ & $3,02 \pm 0,4$ & $2,87 \pm 0,4$ & $3,00 \pm 0,4$ & 0,402 & 0,520 & 0,820 \\
\hline R\$/@ & $64,53 \pm 3,3$ & $65,14 \pm 2,9$ & $63,90 \pm 3,4$ & $64,89 \pm 2,8$ & 0,982 & 0,903 & 0,591 \\
\hline
\end{tabular}

$\mathrm{CF}=$ custo fixo; OT = oportunidade da terra; DEP = depreciação; OCD = oportunidade do capital em depreciação; CV = custo variável; $\mathrm{A}=$ animais; $\mathrm{V}=$ volumosos; $\mathrm{C}=$ concentrado; $\mathrm{ALI}=$ alimentação; $\mathrm{MO}=$ mão de obra; $\mathrm{MS}=$ manejo sanitário; $\mathrm{AT}=$ assistência técnica; $\mathrm{OCI}=$ oportunidade capital investido; $\mathrm{O}=$ outras despesas; $\mathrm{AT}=$ assistência técnica; $\mathrm{CT}=$ custo total $(\mathrm{CF}$ $+\mathrm{CV}$ ); PCQ = peso de carcaça quente; REC = receita; $\mathrm{COE}=$ custo operacional efetivo (animais + mão-de-obra + sanidade + volumoso + concentrado + assistência técnica + outros $) ;$ COT = custo operacional total $(\mathrm{COE}+$ depreciação); GMD $=$ ganho de peso médio diário; $\mathrm{FMB} * \mathrm{NC}=$ interação entre $\mathrm{FMB}$ e $\mathrm{NC}$.

Fonte: Elaboração dos autores. 
O custo variável, o custo operacional efetivo, o custo operacional total e o custo total foi reduzido $(\mathrm{P}<0,05)$ pela inclusão do FMB no concentrado, refletindo a redução do custo com concentrado e custo com alimentação (Tabela 7). Esses resultados foram coerentes às verificações de Faturi et al. (2003), os quais avaliando o grão de aveia preta em substituição ao grão de sorgo e, aos de Ezequiel et al. (2006), que avaliando o farelo de gérmen milho, a casca do grão de soja ou a polpa de citrus em substituição ao grão milho na deita de bovinos confinados, verificaram diminuição do custo com alimentação, como resultado do menor custo dos alimentos que substituíram o milho ou sorgo na dieta. Por outro lado, o aumento do nível de concentrado da dieta determinou elevação $(\mathrm{P}<0,05)$ destes custos, refletindo o aumento do custo com concentrado e, consequentemente, o custo com alimentação.

O custo com volumoso (Tabela 7), diminuiu em função da elevação da proporção de concentrado na dieta, reflexo da menor quantidade de volumoso utilizada para a alimentação dos animais. Apesar do aumento do CMS, o custo com volumoso não foi alterado pela inclusão do FMB no concentrado. Segundo Gesualdi Júnior et al. (2000), a partir de custos viáveis de volumosos e concentrados e havendo remuneração por carcaças de melhor qualidade, o sistema de alimentação com maior nível de concentrado tende a se tornar mais eficiente, pois reduz o tempo de confinamento e o custo de produção. Entretanto, os resultados obtidos não suportam tais suposições, visto que os custos de produção aumentaram com o avanço do concentrado na dieta, em resposta à elevação dos custos com concentrado.

O custo de oportunidade do capital investido, bem como os outros custos (combustível, energia elétrica, frete, prolabore do proprietário, impostos e alimentação da mão-de-obra) foi reduzido $(\mathrm{P}<0,05)$ pela inclusão do FMB no concentrado (Tabela 7). Por outro lado, esses custos foram elevados pelo aumento do nível de concentrado da dieta, refletindo o aumento do custo total. Esses resultados foram similares aos apresentados por Missio et al. (2009), os quais verificaram que o aumento do nível de concentrado elevou os custos com alimentação e, consequentemente, o custo de oportunidade do capital investido.

A receita não foi alterada $(\mathrm{P}>0,05)$ pelas dietas experimentais (Tabela 7), refletindo o similar peso de abate e preço de comercialização das carcaças. Apesar da manutenção da receita e da variação do custo total, não foram evidenciadas diferenças significativas para o custo/kg de ganho de peso e o custo/arroba de carcaça total em função do nível de concentrado na dieta e de FMB no concentrado. O custo/arroba foi inferior ao preço médio de comercialização do boi gordo durante o ano de 2010, o que determinou obtenção de margem de lucro favorável. Entretanto, é importante frisar, que o período de comercialização dos animais (setembro/2010) não coincidiu com o pico de preço do boi gordo, o qual ocorreu em meados de novembro/2010 (ANUALPEC, 2011), o que de certa forma limitou a margem de lucro.

A elevação do nível de concentrado da dieta reduziu $(\mathrm{P}<0,05)$ a participação do custo fixo frente ao custo total (Tabela 8), assim como reduziu a participação relativa do custo com depreciação, não alterando a participação dos custos de oportunidade da terra e do capital em depreciação frente ao custo total. Por outro lado, a inclusão do FMB no concentrado elevou $(\mathrm{P}<0,05)$ a participação do custo fixo frente ao custo total, bem como aumentou a participação relativa do custo de oportunidade da terra, não alterando a participação dos custos com depreciação e de oportunidade do capital em depreciação frente ao custo total. Os resultados apresentados foram reflexo de variações nos demais custos, notadamente do custo com alimentação. Deve-se destacar que entre os custos fixos o item mais importante foi o custo de oportunidade da terra $(0,64 \%)$, seguido pelo custo com depreciação $(0,48 \%)$. 
Tabela 8. Participação relativa dos componentes do custo, indicadores de retorno e risco do investimento de acordo com os níveis de farelo do mesocarpo de babaçu (FMB) e de concentrado (NC).

\begin{tabular}{|c|c|c|c|c|c|c|c|}
\hline \multirow{2}{*}{ Itens } & \multicolumn{2}{|c|}{ FMB (\%) } & \multicolumn{2}{|c|}{$\mathrm{NC}(\%)$} & \multicolumn{3}{|c|}{ Valor de P } \\
\hline & 0 & 35 & 65 & 71 & FMB & $\mathrm{NC}$ & $\mathrm{FMB} * \mathrm{NC}$ \\
\hline $\mathrm{CF}, \% \mathrm{CT}$ & $1,11 \pm 0,08$ & $1,13 \pm 0,08$ & $1,19 \pm 0,04$ & $1,05 \pm 0,03$ & $<0,001$ & $<0,001$ & 0,458 \\
\hline OT, \% CT & $0,63 \pm 0,08$ & $0,65 \pm 0,08$ & $0,70 \pm 0,04$ & $0,58 \pm 0,03$ & $<0,001$ & 0,272 & 0,964 \\
\hline DEP, \% CT & $0,47 \pm 0,01$ & $0,48 \pm 0,01$ & $0,48 \pm 0,01$ & $0,47 \pm 0,01$ & 0,160 & 0,033 & 0,582 \\
\hline OCD, $\% \mathrm{CT}$ & $0,01 \pm 0,01$ & $0,01 \pm 0,00$ & $0,01 \pm 0,01$ & $0,01 \pm 0,01$ & 0,444 & 0,444 & 0,445 \\
\hline $\mathrm{CV}, \% \mathrm{CT}$ & $98,89 \pm 0,08$ & $98,87 \pm 0,08$ & $98,81 \pm 0,04$ & $98,95 \pm 0,03$ & $<0,001$ & $<0,001$ & 0,458 \\
\hline $\mathrm{A}, \% \mathrm{CT}$ & $72,84 \pm 1,40$ & $73,85 \pm 1,00$ & $73,67 \pm 1,13$ & $73,02 \pm 1,45$ & 0,161 & 0,650 & 0,575 \\
\hline $\mathrm{V}, \% \mathrm{CT}$ & $4,39 \pm 0,55$ & $4,51 \pm 0,55$ & $4,90 \pm 0,30$ & $4,00 \pm 0,27$ & $<0,001$ & 0,326 & 0,915 \\
\hline $\mathrm{C}, \mathrm{R} \$$ & $14,54 \pm 1,48$ & $13,32 \pm 1,45$ & $13,07 \pm 0,91$ & $14,79 \pm 1,28$ & $<0,001$ & 0,002 & 0,469 \\
\hline ALI, \% CT & $18,93 \pm 1,46$ & $17,83 \pm 1,01$ & $17,97 \pm 1,14$ & $18,79 \pm 1,47$ & 0,083 & 0,024 & 0,560 \\
\hline $\mathrm{MO}, \% \mathrm{CT}$ & $1,08 \pm 0,02$ & $1,10 \pm 0,01$ & $1,09 \pm 0,01$ & $1,08 \pm 0,02$ & 0,139 & 0,053 & 0,615 \\
\hline $\mathrm{MS}, \% \mathrm{CT}$ & $0,61 \pm 0,01$ & $0,62 \pm 0,01$ & $0,61 \pm 0,01$ & $0,61 \pm 0,01$ & 0,254 & 0,067 & 0,817 \\
\hline $\mathrm{AT}, \% \mathrm{CT}$ & $3,09 \pm 0,01$ & $3,13 \pm 0,02$ & $3,13 \pm 0,01$ & $3,10 \pm 0,02$ & 0,144 & 0,073 & 0,577 \\
\hline $\mathrm{O}, \% \mathrm{CT}$ & $2,34 \pm 0,01$ & $2,34 \pm 0,01$ & $2,34 \pm 0,01$ & $2,35 \pm 0,01$ & 0,111 & 0,077 & 1,000 \\
\hline OCI, \% CT & $1,01 \pm 0,01$ & $1,01 \pm 0,01$ & $1,01 \pm 0,01$ & $1,01 \pm 0,01$ & 0,114 & 0,192 & 0,192 \\
\hline $\mathrm{MB}, \mathrm{R} \$$ & $278,98 \pm 69,7$ & $67,21 \pm 69,7$ & $92,43 \pm 74,9$ & $61,57 \pm 64,1$ & 0,940 & 0,861 & 0,576 \\
\hline $\mathrm{ML}, \mathrm{R} \$$ & $273,74 \pm 69,7$ & $61,97 \pm 69,7$ & $87,19 \pm 74,9$ & $56,33 \pm 64,1$ & 0,941 & 0,861 & 0,756 \\
\hline Lucro, R\$ & $266,65 \pm 69,7$ & $250,29 \pm 69,6$ & $276,91 \pm 74,9$ & $258,32 \pm 64,1$ & 0,936 & 0,866 & 0,574 \\
\hline VPL, R\$ & $269,05 \pm 68,3$ & $264,54 \pm 67,9$ & $267,24 \pm 73,3$ & $266,35 \pm 62,5$ & 0,979 & 0,866 & 0,571 \\
\hline IBC & $1,26 \pm 0,06$ & $1,25 \pm 0,06$ & $1,26 \pm 0,07$ & $1,25 \pm 0,06$ & 0,923 & 0,872 & 0,542 \\
\hline ROIA, \% & $5,82 \pm 1,36$ & $5,79 \pm 1,29$ & $5,84 \pm 1,44$ & $5,78 \pm 1,19$ & 0,959 & 0,897 & 0,565 \\
\hline TIR, \% a.m. & $6,22 \pm 1,37$ & $6,19 \pm 1,29$ & $6,24 \pm 1,45$ & $6,17 \pm 1,19$ & 0,956 & 0,895 & 0,567 \\
\hline
\end{tabular}

$\mathrm{OT}=$ oportunidade da terra; $\mathrm{DEP}=$ depreciação; $\mathrm{OCD}=$ oportunidade do capital em depreciação; $\mathrm{CV}=$ custo variável; $\mathrm{A}=$ animal; $\mathrm{V}=$ volumoso; $\mathrm{C}=$ concentrado; $\mathrm{ALI}=$ alimentação; $\mathrm{MO}=$ mão-de-obra; $\mathrm{MS}=$ manejo sanitário; $\mathrm{AT}=$ assistência técnica; $\mathrm{AT}=$ assistência técnica; $\mathrm{OCI}=$ oportunidade capital investido; $\mathrm{O}=$ outras despesas; $\mathrm{CT}=$ cuto total; $\mathrm{MB}=$ margem bruta; $\mathrm{ML}=$ margem líquida; VPL = valor presente líquido; $\mathrm{IBC}=$ índice benefício custo; $\mathrm{ROIA}=$ retorno adicional sobre o investimento; $\mathrm{TIR}=$ taxa interna de retorno; $\mathrm{FMB}^{*} \mathrm{NC}=$ interação entre $\mathrm{FMB}$ e $\mathrm{NC}$.

Fonte: Elaboração dos autores.

A participação do custo variável frente ao custo total foi reduzida $(\mathrm{P}<0,05)$ pela inclusão do FMB no concentrado (Tabela 8), refletindo a diminuição do custo com concentrado. Por outro lado, a participação do custo com volumoso frente ao custo total aumentou $(\mathrm{P}<0,05)$ pela inclusão do FMB no concentrado, fato associado à diminuição do custo com concentrado e aumento do CMS e, consequentemente, maior quantidade de volumoso para a alimentação dos animais. De outra maneira, o nível de concentrado da dieta promoveu aumento da participação do custo variável frente ao custo total, resultados atribuídos ao aumento do custo com concentrado. Por outro lado, em função da diminuição da quantidade de volumoso com o aumento do nível de concentrado, a participação do custo com volumoso frente ao custo total foi reduzido pela elevação da fração concentrada na dieta. É importante mencionar que os custos variáveis foram os principais componentes do custo de produção, representando em média 98,88\%. Dentro dos custos variáveis os principais compontes foram os custos com aquisição de animais $(73,34 \%)$ e o custo com alimentação $(18,34)$, em que a fração concentrada representou $13,93 \%$ frente ao custo total. Este resultados foram coerentes com aqueles encontrados por Pacheco et al. (2006), os quais avaliando a terminação de novilhos jovens e superjovens de diferentes grupos genéticos em confinamento, verificaram que, em ordem 
decrescente, o custo com aquisição de animais e o custo com concentrado foram os principais componentes do custo total, sendo que quando desconsiderado o valor de compra dos animais, a alimentação (concentrado + volumosos) foi o item mais representativo frente ao custo total.

Os indicadores de retorno e risco do investimento, apresentados na Tabela 8, não foram alterados significativamente pelas dietas experimentais, embora esperavam-se resultados diferentes em função da variação do custo total de acordo com os fatores estudados. Apesar disso, pode-se evidenciar que todos os indicadores demonstraram a viabililidade econômica da utilização do confinamento para terminação de bovinos. Estes resultados foram concordantes aos verificados por Resende Filho, Braga e Rodrigues (2001), os quais avaliando sistemas de terminação em confinamento com épocas distintas de comercialização verificaram VPLs positivos, demonstrando que a engorda intensiva de bovinos é viável economicamente. Além disso, a taxa de remuneração mensal obtida para o presente estudo superou às principais aplicações disponíveis no mercado financeiro, resultados similares ao estudo de Fernandes et al. (2007). Tais aspectos são de fundamental importância, já que, segundo Coan et al. (2008), mesmo que o resultado econômico do confinamento seja semelhante às aplicações financeiras, deve-se optar por sua utilização, pois os benefícios indiretos, notadamente nos sistemas de ciclo completo, justificam sua adoção na produção de carne bovina.

Foi verificado interação significativa entre os fatores estudados, na análise de sensibilidade (Tabela 9), sobre o custo total e o lucro. Nesse sentido, verificou-se que, nas maiores relações de troca entre o preço do grão de milho e do FMB $(2,2: 1 ; 2,6: 1$ e $3,0: 1)$, a medida que o custo do milho aumentou, o custo total foi diminuído apenas nas dietas que associaram o maior nível de concentrado e a inclusão de $35 \%$ do FMB. No entanto, quando a relação de troca foi baixa $(1,3: 1$ e 1,7:1) e, consequentemente, o preço do milho foi baixo, a inclusão de $35 \%$ de FMB no concentrado não alterou o custo total, independente do nível de concentrado. De outra maneira, a inclusão de 35\% de FMB no concentrado, só influenciou $(\mathrm{P}<0,05)$ o lucro nas dietas que associaram o maior teor de concentrado e a maior relação de troca entre o custo do milho e do FMB (3,0:1), sendo que nas demais relações de troca não ocorreu alteração do lucro pela inclusão do FMB, independente do nível de concentrado. Verificou-se ainda, que o lucro só foi alterado pelo aumento do nível de concentrado nas dietas que associaram zero de FMB nas situações em que o custo do grão de milho foi maior ( $\mathrm{R} \$ 0,60$ e $0,70 / \mathrm{kg}$ ), sendo o melhor lucro para as dietas com menor proporção de concentrado.

Os resultados apresentados demontraram que a inclusão do FMB tem maior impacto sobre os custos de produção e lucratividade do confinamento quando se utiliza dietas com elevada proporção de concentrado e a relação de troca entre os alimentos é alta. Tais aspectos são justificados, pois nas dietas com maior proporção de concentrado a quantidade de milho que dá lugar ao FMB, de menor custo, é maior do que naquelas com menor porporção de concentrado. De outra maneira, quando a alteração da proporção de concentrado na dieta é pequena, os custos são aumentados e o lucro diminuído somente em situações em que o nível de concentrado e o preço do grão de milho forem elevados. 
Tabela 9. Análise de sensibilidade em função da variação da relação de troca (RT) entre o preço do grão de milho (GM) e do farelo do mesocarpo de babaçu (FMB) de acordo com os fatores avaliados.

\begin{tabular}{|c|c|c|c|c|c|}
\hline \multirow{4}{*}{$\begin{array}{c}\text { RT entre preço do GM } \\
\text { e FMB }\end{array}$} & \multicolumn{4}{|c|}{ Farelo do mesocarpo de babaçu no concentrado (FMB, \%) } & \multirow{4}{*}{ Média } \\
\hline & & & & & \\
\hline & \multicolumn{4}{|c|}{ Nível de concentrado da dieta (NC, \%) } & \\
\hline & 65 & 71 & 65 & 71 & \\
\hline \multicolumn{6}{|c|}{ Custo total $(\mathrm{R} \$)^{1}$} \\
\hline $1,3: 1$ & $1050,33 \mathrm{Aa}$ & $1056,80 \mathrm{Aa}$ & $1043,61 \mathrm{Aa}$ & $1047,76 \mathrm{Aa}$ & 1049,63 \\
\hline $1,7: 1$ & $1074,30 \mathrm{Aa}$ & $1088,21 \mathrm{Aa}$ & $1063,09 \mathrm{Aa}$ & $1068,86 \mathrm{Aa}$ & 1073,62 \\
\hline $2,2: 1$ & $1103,06 \mathrm{Aa}$ & $1119,63 \mathrm{Aa}$ & $1077,69 \mathrm{Ab}$ & $1089,97 \mathrm{Ab}$ & 1097,59 \\
\hline $2,6: 1$ & $1127,02 \mathrm{Ba}$ & $1151,04 \mathrm{Aa}$ & $1092,30 \mathrm{Ab}$ & $1105,79 \mathrm{Ab}$ & 1119,04 \\
\hline $3,0: 1$ & $1155,78 \mathrm{Ba}$ & $1182,45 \mathrm{Aa}$ & $1106,90 \mathrm{Ab}$ & $1126,89 \mathrm{Ab}$ & 1143,01 \\
\hline \multicolumn{6}{|c|}{ Lucro $(\mathrm{R} \$ / \text { animal })^{2}$} \\
\hline $1,3: 1$ & $325,07 \mathrm{Aa}$ & $314,92 \mathrm{Aa}$ & $300,37 \mathrm{Aa}$ & $315,34 \mathrm{Aa}$ & 313,93 \\
\hline $1,7: 1$ & $300,86 \mathrm{Aa}$ & $283,17 \mathrm{Aa}$ & $280,69 \mathrm{Aa}$ & $294,01 \mathrm{Aa}$ & 289,68 \\
\hline $2,2: 1$ & $271,79 \mathrm{Aa}$ & $251,43 \mathrm{Aa}$ & $265,93 \mathrm{Aa}$ & $272,69 \mathrm{Aa}$ & 265,46 \\
\hline $2,6: 1$ & $247,57 \mathrm{Aa}$ & $219,69 \mathrm{Ba}$ & $251,17 \mathrm{Aa}$ & $256,70 \mathrm{Aa}$ & 243,78 \\
\hline $3,0: 1$ & $218,51 \mathrm{Aa}$ & $187,94 \mathrm{Bb}$ & $236,41 \mathrm{Aa}$ & $235,38 \mathrm{Aa}$ & 219,56 \\
\hline
\end{tabular}

${ }^{1}$ Valor de $\mathrm{P}$ para a interação $\mathrm{RT} * \mathrm{FMB} * \mathrm{NC}=0,001 ;{ }^{2}$ Valor de $\mathrm{P}$ para a interação $\mathrm{RT} * \mathrm{FMB} * \mathrm{NC}=0,048$; dentro do nível de $\mathrm{FMB}$, letras maiúsculas distintas indicam diferença, pelo teste Tukey, entre as médias dos níveis de concentrado; dentro do nível de concentrado, letras minúsculas distintas indicam diferença, pelo teste Tukey, entre as médias dos níveis de FMB; Custo total $=980,11+53,92 \mathrm{RT}, \mathrm{P}<0,0001, \mathrm{R}^{2}=0,65 ;$ Lucro $=384,18-54,49 \mathrm{RT}, \mathrm{P}<0,0001, \mathrm{R}^{2}=0,21 ; \mathrm{O}$ custo do quilograma do milho utilizado para a análise foi de $\mathrm{R} \$ 0,70 ; 0,60 ; 0,50 ; 0,40$ e 0,30 referente as relações de troca de $3,0: 1 ; 2,6: 1 ; 2,2: 1 ; 1,7: 1 ; 1,3: 1$, respectivamente. $\mathrm{O}$ custo do quilograma do farelo do mesocarpo de babaçu foi de $\mathrm{R} \$ 0,23$.

Fonte: Elaboração dos autores.

\section{Conclusões}

A inclusão de 35\% de farelo do mesocarpo do babaçu na fração concentrada da dieta é alternativa alimentar viável, pois não altera o desempenho de tourinhos confinados. Entretanto, sua utilização é mais impactante economicamente quando se utilizam dietas com elevada proporção de concentrado e a relação de troca entre o preço desse subproduto e o grão de milho é alta. De outra maneira, quando a alteração da proporção de concentrado na dieta é pequena, o custo de produção e o lucro são alterados somente em situações em que o nível de concentrado e o preço do grão de milho forem elevados.

\section{Referências}

ANUÁRIO DA PECUÁRIA BRASILEIRA ANUALPEC. 18. ed. São Paulo: Instituto FNP, 2011. $378 \mathrm{p}$.
ASSOCIATION OF OFFICIAL ANALYTICAL CHEMISTS - AOAC. Official methods of analysis. 16. ed. Arlington: AOAC International, 1995. $1025 \mathrm{p}$.

BULLE, M. L. M. Desempenho, composição corporal e exigências líquidas de energia e proteína de tourinhos de dois tipos genéticos alimentados com dietas de alto teor de concentrado. 2000. Dissertação (Mestrado em Zootecnia) - Escola Superior de Agricultura Luiz de Queiroz, Piracicaba.

CASALI, A. O.; DETMAN, E.; VALADARES FILHO, S. C.; PEREIRA, J. C.; HENRIQUES, L. T.; FREITAS, S. G.; PAULINO, M. F. Influência do tempo de incubação e do tamanho de partículas sobre os teores de compostos indigestíveis em alimentos e fezes bovinas obtidos por procedimentos in situ. Revista Brasileira de Zootecnia, Viçosa, v. 37, n. 2, p. 335-342, 2008.

COAN, R. M.; REIS, R. A.; RESENDE, F. D.; SAMPAIO, R. L.; SCHOCKEN-ITURRINO, R. P.; GARCIA, G. R.; BERCHIELLI, T. T. Viabilidade econômica, desempenho e características de carcaça de garrotes em confinamento alimentados com dietas contendo silagem de capins tanzânia ou marandu ou silagem milho. Revista Brasileira de Zootecnia, Viçosa, v. 37, n. 2, p. 311-318, 2008. 
COCHRAN, R. C.; ADAMS, D. C.; WALLACE, J. D.; GALYEAN, M. L. Predicting digestibility of different diets with internal markers: evaluation of four potential markers. Journal of Animal Science, Champaign, v. 63, p. 1476-1483, 1986.

CRUZ, R. S. da; ALEXANDRINO, E.; MISSIO, R. L.; NEIVA, J. N. M.; RESTLE, J.; MELO, J. C.; JUNIOR, A. de S.; RESENDE, J. M. de. Feeding behaviors of feedlot bulls fed concentrate levels and babassu mesocarp meal. Revista Brasileira de Zootecnia, Viçosa, v. 41, n. 7, p. 1727-1736, 2012.

EZEQUIEL, J. M. B.; GALATI, R. L.; MENDES, A. R.; FATURI, C. Desempenho e características de carcaça de bovinos Nelore em confinamento alimentados com bagaço de cana-de-açúcar e diferentes fontes energéticas. Revista Brasileira de Zootecnia, Viçosa, v. 35, n. 5, p. 2050-2057, 2006.

FATURI, C.; RESTLE, J.; PASCOAL, L.L.; CERDÓTES, L.; RIZZARDO, R. A. G.; FREITAS, A. $\mathrm{K}$. Avaliação econômica de dietas com diferentes níveis de substituição do grão de sorgo por grão de aveia preta para terminação de novilhos em confinamento. Ciência Rural, Santa Maria, v. 33, n. 5, p. 937-942, 2003.

FERNANDES, A. R. M.; SAMPAIO, A. A. M.; HENRIQUE, W.; PERECIN, D.; OLIVEIRA, E. A.; TÚLLIO, R. R. Avaliação econômica e desempenho de machos e fêmeas Canchim em confinamento alimentados com dietas à base de silagem milho e concentrado ou cana-de-açúcar e concentrado contendo grãos de girassol. Revista Brasileira de Zootecnia, Viçosa, v. 36, n. 4, p. 855-864, 2007.

GESUALDI JÚNIOR, A.; PAULINO, M. F.; VALADARES FILHO, S. de C.; SILVA, J. F. C. da; VELOSO, C. M.; CECON, P. R. Níveis de concentrado na dieta de novilhos F1 Limousin x Nelore: consumo, conversão alimentar e ganho de peso. Revista Brasileira de Zootecnia, v. 29, n. 5, p. 1458-1466, 2000.

GUIMARÃES, C. R. R. Valor nutritivo da silagem de capim mombaça (Panicum maximum) com niveis crescentes de adição do farelo do mesocarpo do babaçu (Orbignya sp). 2010. Dissertação (Mestrado em Ciência Animal Tropical) - Universidade Federal do Tocantins, Araguaína.

KASSAI, J. R.; KASSAI, S.; SANTOS, A.; ASSAF NETO, A. Retorno de investimento: abordagem matemática e contábil do lucro empresarial. 2. ed. São Paulo: Editora Atlas, 2000. 256 p.

LICITRA, G.; HERNANDEZ, T. M.; VAN SOEST, P. J. Standardization of procedures for nitrogen fractionation of ruminant feeds. Animal Feed Science and Technology, Elsevier, v. 57, n. 4, p. 347-358, 1996.
MERTENS, D. R. Creating a system for meeting the fiber requirements of dairy cows. Journal of Dairy Science, Champaign, v. 80, n. 7, p. 1463-1481, 1997.

MIOTTO, F. R. C.; RESTLE, J.; NEIVA, J. N. M.; CASTRO, K. J. de; SOUSA, L. F.; SILVA, R. de O. da; FREITAS, B. B. de; LEÃO, J. P. Replacement of corn by babassu mesocarp bran in diets for feedlot young bulls. Revista Brasileira de Zootecnia, Viçosa, v. 42, n. 3, p. 213-219, 2013.

MIOTTO, F. R. C.; RESTLE, J.; NEIVA, J. N. M.; MACIEL, R. P.; FERNANDES, J. J. R. Consumo e digestibilidade de dietas contendo níveis de farelo do mesocarpo de babaçu para ovinos. Revista Ciência Agronômica, Fortaleza, v. 43, n. 4, p. 792-801, 2012.

MIOTTO, F. R. C. Farelo do mesocarpo do babaçu na produção de bovinos de corte. 2011. Tese (Doutorado em Zootecnia) - Universidade Federal de Goiás, Goiânia.

MISSIO, R. L.; BRONDANI, I. L.; FREITAS, L. S.; SACHET, R. H.; SILVA, J. H. S. da; RESTLE, J. Desempenho e avaliação econômica da terminação de tourinhos em confinamento alimentados com diferentes níveis de concentrado na dieta. Revista Brasileira de Zootecnia, Viçosa, v. 38, n. 7, p. 1309-1316, 2009.

NATIONAL RESEARCH COUNCIL - NRC. Nutrients requirements of beef cattle. 7. ed. Washington: D.C., 1996. $242 \mathrm{p}$.

PACHECO, P. S.; RESTLE, J.; VAZ, F. N.; FREITAS, A. K.; PADUA, J. T.; NEUMANN, M.; ARBOITTE, M. Z. Avaliação econômica em confinamento de novilhos jovens e superjovens de diferentes grupos genéticos. Revista Brasileira de Zootecnia, Viçosa, v. 35, n. 1, p. 309-320, 2006.

PAVLAK, M. C. M.; ZUNIGA, A. D.; LIMA, T. L. A.; ARÉVALO-PINEDO, A.; CARREIRO, S. C.; FLEURY, C. S.; SILVA, D. L. Aproveitamento da farelo do mesocarpo do babaçu (Orbignya martiana) para obtenção de etanol. Evidência, Joaçaba, v. 7, n. 1, p. 7-24, 2007.

PEREIRA, D. H.; PEREIRA, O. G.; VALADARES FILHO, S. de C.; GARCIA, R.; OLIVEIRA, A. P.; MARTINS, F. H.; VIANA, V. Consumo, digestibilidade dos nutrientes e desempenho de bovinos de corte recebendo silagem de sorgo (Sorghum bicolor (L.) Moench) e diferentes proporções de concentrado. Revista Brasileira de Zootecnia, Viçosa, v. 35, n. 1, p. 282-291, 2006.

RESENDE FILHO, M.A.; BRAGA, M. J.; RODRIGUES, R. V. Sistemas de terminação em confinamento: perspectivas para dinamização da cadeia produtiva da carne bovina em Minas Gerais. Revista Brasileira de Economia, Rio de Janeiro, v. 55, n. 1, p. 107-131, 2001. 
RESENDE, F. D. de; QUEIROZ, A. C. de; OLIVEIRA, J. V. de; PEREIRA, J. C.; MÂNCIO, A. B. Bovinos mestiços alimentados com diferentes proporções de volumoso:concentrado. 1. Digestibilidade aparente dos nutrientes, ganho de peso e conversão alimentar. Revista Brasileira de Zootecnia, Viçosa, v. 30, n. 1, p. 261-269, 2001.

RESTLE, J.; MISSIO, R. L.; RESENDE, P. L. P.; SILVA, N. L. Q.; VAZ, F. N.; BRONDANI, I. L.; ALVES FILHO, D. C.; KUSS, F. Silagem de híbridos de sorgo associado a percentagens de concentrado no desempenho de novilhos. Arquivo Brasileiro de Medicina Veterinária e Zootecnia, Belo Horizonte, v. 64, n. 5, p. 1239-1245, 2012.

SILVA, B. C.; PEREIRA, O. G.; PEREIRA, D. H.; GARCIA, R.; VALADARES FILHO, S. C.; CHIZZOTTI, F. M. Consumo e digestibilidade aparente total dos nutrientes e ganho de peso de bovinos de corte alimentados com silagem de Brachiaria brizantha e concentrado em diferentes proporções. Revista Brasileira de Zootecnia, Viçosa, v. 34, n. 3, p. 1060-1069, 2005.

SILVA, N. R. da; FERREIRA, A. C. H.; FATURI, C.; SILVA, G. F. da; MISSIO, R. L.; NEIVA, J. N. M.; ARAÚJO, V. L. de; ALEXANDRINO, E. Desempenho em confinamento de bovinos de corte, castrados ou não, alimentados com teores crescentes de farelo do mesocarpo de babaçu. Ciência Rural, Santa Maria, v. 42, n. 10, p. 1882-1887, 2012.

SNIFFEN, C. J.; O'CONNOR, J. D.; VAN SOEST, P. J.; FOX, D. G.; RUSSEL, J. B. A net carbohydrate and protein system for evaluating cattle diets: II. carbohydrate and protein availability. Journal of Animal Science, Champaign, v. 70, n. 12, p. 3562-3577, 1992.
SOUZA, A.; CLEMENTE, A. Decisões financeiras e análise de investimentos. 5. ed. São Paulo: Atlas, 2004. $178 \mathrm{p}$.

TIBO, G. C.; VAÇADARES FILHO, S. C.; VALADARES, R. F. D.; SILVA, J. F. C. da; CECON, P. R.; LEÃO, M. I.; SILVA, R. B. da. Níveis de concentrado em dietas de novilhos mestiços F1 Simental x Nelore.

1. Consumo e digestibilidades. Revista Brasileira de Zootecnia, Viçosa, v. 29, n. 3, p. 910-920, 2000.

VAN SOEST, P. J. Collaborative study of acid-detergent fiber and lignin. Journal of the Association of Official Analytical Chemists, Pennsylvania, v. 56, p. 781-784, 1973.

VAN SOEST, P. J.; ROBERTSON, J. B.; LEWIS, B. A. Methods for dietary fiber, neutral detergent fiber, and nonstarch polyssacarides in relation to animal nutrition. Journal of Animal Science, Champaign, v. 74, n. 10, p. 3583-3597, 1991.

VAN SOEST, P. J. Nutritional ecology of the ruminant. 2. ed. New York: Cornell University Press, 1994. 476 p.

VÉRAS, R. M. L.; VALADARES FILHO, S. C.; AZEVEDO, J. A. G.; DETMAN, E.; PAULINO, P. V. R.; BARBOSA, A. M.; MARCONDES, M. I. Níveis de concentrado na dieta de bovinos Nelore de três condições sexuais: consumo, digestibilidades total e parcial, produção microbiana e parâmetros ruminais. Revista Brasileira de Zootecnia, Viçosa, v. 37, n. 5, p. 951-960, 2008. 